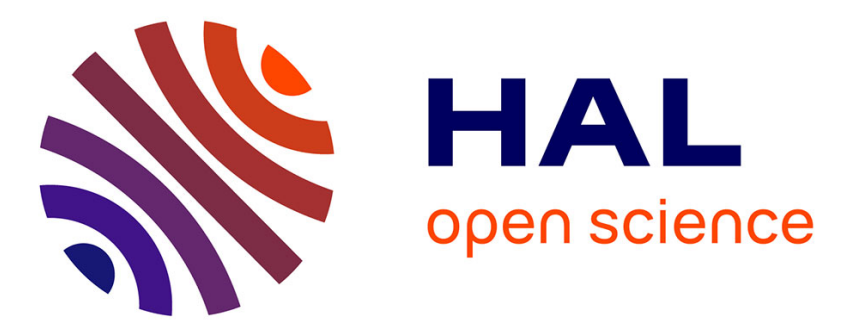

\title{
Pre-operative chemotherapy for colorectal cancer liver metastases: an update of recent clinical trials
}

\author{
G. Nasti, A. Ottaiano, M. Berretta, P. Delrio, F. Izzo, A. Cassata, C. \\ Romano, G. Facchini, D. Scala, A. Mastro, et al.
}

\section{- To cite this version:}

G. Nasti, A. Ottaiano, M. Berretta, P. Delrio, F. Izzo, et al.. Pre-operative chemotherapy for colorectal cancer liver metastases: an update of recent clinical trials. Cancer Chemotherapy and Pharmacology, 2010, 66 (2), pp.209-218. 10.1007/s00280-010-1297-x . hal-00579488

\section{HAL Id: hal-00579488 \\ https://hal.science/hal-00579488}

Submitted on 24 Mar 2011

HAL is a multi-disciplinary open access archive for the deposit and dissemination of scientific research documents, whether they are published or not. The documents may come from teaching and research institutions in France or abroad, or from public or private research centers.
L'archive ouverte pluridisciplinaire HAL, est destinée au dépôt et à la diffusion de documents scientifiques de niveau recherche, publiés ou non, émanant des établissements d'enseignement et de recherche français ou étrangers, des laboratoires publics ou privés. 
PRE-OPERATIVE CHEMOTHERAPY FOR COLORECTAL CANCER LIVER METASTASES: AN UPDATE OF RECENT CLINICAL TRIALS

Nasti $G^{a}$, Ottaiano $A^{a}$, Berretta $M^{b}$, Delrio $P^{c}$, Izzo $F^{c}$, Cassata $A^{a}$, Romano $C^{a}$, Facchini $G^{a}$, Scala $D^{c}$, Mastro $A^{d}$, Romano $G^{c}$, Perri $F^{a}$, Iaffaioli $R^{a}$

${ }^{\mathrm{a}}$ Department of Colorectal Medical Oncology, National Cancer Institute of Naples - Italy, ${ }^{\mathrm{b}}$ Department of Medical Oncology, National Cancer Institute of Aviano - Italy, ${ }^{c}$ Colorectal Department, Surgery Unit , National Cancer Institute of Naples - Italy, ${ }^{\mathrm{d}}$ Epato-biliary Department, Surgery Unit, National Cancer Institute of Naples - Italy.

Address for correspondence: dr. Guglielmo Nasti - National Cancer Institute of Napoli - via M. Semmola - 80131 - Napoli - Italy tel. 00390815903367 fax 00390815903822 email guglielmo.nasti@ libero.it 


\begin{abstract}
The standard treatment of CRC patients with hepatic metastases is systemic chemotherapy; however, 5-year survival is disappointingly poor despite recent advances. On the other hand, in patients who undergo immediate radical surgical resection of hepatic metastases, 5-year survival reaches 30-40\%. Unfortunately, only $15-20 \%$ of patients with hepatic metastases are initially eligible for a radical surgical approach. The majority of patients undergoing liver resection relapse after surgery. For this reason, new onco-surgery approches have been investigated in recent years and the addition of biological agents to chemotherapy, such as bevacizumab and cetuximab,and the improvements of surgical technics have opened a new scenario in the management of colorectal liver metastases. Recently, the EORTC trial has demonstrated that perioperative chemotherapy (Folfox regimen) is feasible and improves progression free survival in patients with resectable liver metatsases. Chemotherapy and surgery can finally collaborate. In the unresectable setting the association of chemotherapy with bevacizumab and cetuximab is particularly promising in improving resectability rate. In particular, K-RAS is a molecular response predictive factor that could be particularly useful in selecting the best treatment option in pts with unresectable liver disease.
\end{abstract}

Keywords: Liver metastases, colorectal cancer, neoadjuvant, resection 


\section{Introduction}

Colorectal cancer (CRC) is the second cause of cancer death in Europe and the third in USA. The expected incidence of CRC in Italy is 32000 cases/year with 16000 CRC-related deaths/year [1]. Twenty percent of patients have clinical evidence of hepatic metastases at diagnosis and about $50 \%$ of patients will develop liver metastatic disease later [2].

The standard treatment of CRC patients with hepatic metastases is systemic chemotherapy; however, 5-year survival is disappointingly poor despite recent advances. On the other hand, in patients who undergo immediate radical surgical resection of hepatic metastases, 5-year survival reaches 30-40\%. Unfortunately, only $15-20 \%$ of patients with hepatic metastases are initially eligible for a radical surgical approach [3, 4]. Retrospective series show a clear advantage in terms of overall survival in patients who undergo hepatic resection with respect to patients treated only with chemotherapy [5-7], but it is commonly felt that the advantage observed with surgery is at least partially due to patient selection (better performance status and smaller disease extension in patients treated with surgery). Furthermore, the majority of patients undergoing liver resection relapse after surgery. For this reason, new onco-surgery approaches have been investigated in recent years. A recent EORTC randomized controlled trial demonstrated a significant benefit in terms of progression-free survival in patients treated with peri-operative chemotherapy [8]. Furthermore, the introduction of novel biological agents (such as bevacizumab and cetuximab) has prompted a new interest in the multidisciplinary approach to colo-rectal liver metastases.

\section{The rationale of neoadjuvant treatment in CRC}


Pre-operative chemotherapy has the potentiality of i) rendering resectable hepatic metastases in patients with initially unresectable disease, ii) increasing the percentage of radical resections and iii) allowing limited hepatectomies in patients with initially resectable hepatic metastases, with the aim of reducing surgery-related morbidity and improving post-operative recovery, iv) hitting micro-metastases, v) offering a test of in vivo chemosensitivity which could possibly be useful for the determination of an optimal postoperative schedule.

\section{Patient selection for primary liver resection of CRC metastases}

The majority of patients with liver metastases are not eligible for radical surgical resection. In the past, the main contraindications for a surgical approach have been: > 4 metastases, presence of extra-hepatic disease and resection margins $<1 \mathrm{~cm}$ [9]. Subsequently, Bismuth et al. [4] have extended the above criteria allowing resection of more metastases and of multinodular or hilar metastases. Recently, a consensus group has proposed new guidelines for the evaluation of resectability of hepatic metastases (Table 1). Their unresectability criteria are: 1) hepatic disease that involves more than $50 \%$ of liver parenchyma or six segments, 2) extra-hepatic disease, 3) unfit patients [10]. However, consensus on the definition of resectability criteria and surgical attitude varies considerably among centres. The patients candidated for radical hepatic resection can be stratified into risk groups on the basis of clinical scoring systems [11-14], which use prognostic factors identified with multivariate analysis, such as the presence of positive lymph nodes, a $<12$ month disease-free survival, the presence of more than one tumour, high preoperative CEA, a $>5 \mathrm{~cm}$ tumour. According to the above factors, the 5 -year survival has been shown to range between 14 and $60 \%$. The validity of such systems needs to be confirmed in further studies before their introduction into the clinical practice. More recently, Quispe et al. [15] have highlighted the importance of some main risk factors which may affect prognosis of patients treated with primary liver metastasectomy. In this analysis, synchronic (vs metachronic) disease, presence (vs absence) of limphonodal spread and R1 or 2 (vs R0) resection were associated with poor 5 years overall survival. 


\section{Neoadjuvant chemotherapy in unresectable liver metastasis: is it a realistic option?}

The optimal neoadjuvant chemotherapy regimen has not yet been determined. However, as in the metastatic setting, the combination of chemotherapy with biological agents seems the most effective approach for a neoadjuvant intent. The greater part of data currently available in the literature comes from retrospective analyses or from phase III studies on metastatic disease, in which it was observed that some patients initially treated with a palliative intent became susceptible to radical resection of their hepatic metastases (Table 2) [16,17]. Phase III studies: The study of Tournigand et al. has evidenced a 54\% OR rate for the combination of 5-FU/FA and OXA (FOLFOX) and of 56\% for the combination of 5-FU/FA and IRI (FOLFIRI). Hepatic metastases treated with FOLFOX resulted resectable in $13 \%$ of cases, while those treated with FOLFIRI were resectable in $7 \%$ of cases [16]. The study of Goldberg et al. has compared FOLFOX with a combination regimen of IRI and bolus 5-FU/FA (IFL) and with the association of OXA and IRI (IROX), evidencing an OR rate significantly higher for the FOLFOX regimen (45\% vs $31 \%$ vs $35 \%$, respectively). In this study the percentage of patients who subsequently underwent surgery with radical intent after FOLFOX (4.1\%) was also higher than after IFL (0.75\%) [17]. A recent phase III study published by the Gruppo Oncologico Nord Ovest (GONO) compared fluorouracil, leucovorin, oxaliplatin, and irinotecan (FOLFOXIRI) with infusional fluorouracil, leucovorin, and irinotecan (FOLFIRI) as first-line chemotherapy in unresectable metastatic colorectal cancer. Response rates as assessed by an external panel was $34 \%$ (FOLFIRI) versus 60\% (FOLFOXIRI) $(P<.0001)$. Interestingly, the R0 resection rate of metastases in liverlimited disease was greater in the FOLFOXIRI arm $(12 \% v 36 \% ; P=.017)$. Progression Free Survival (PFS) and Overall Survival (OS) were both significantly improved in the FOLFOXIRI arm (median PFS, $6.9 v 9.8$ months; hazard ratio [HR], 0.63; $P=.0006$; median OS, $16.7 v 22.6$ months; HR, 0.70; $P=.032$ ) [18].

\section{Retrospective analyses of single-centre series}

The Bismuth study was the first to specifically estimate the role of neoadjuvant chemotherapy in patients with unresectable hepatic metastases. Three-hundred thirty patients with unresectable hepatic lesions (large dimensions, multiple nodules, hilar localization, extrahepatic disease) were analysed. Most of the patients 
were treated with oxaliplatin-containing regimens; after chemotherapy 53 patients $(16 \%)$ underwent hepatic resection. Intraoperative mortality was not observed, while 14 patients (26\%) suffered from post-operative complications. The 5-year survival of patients who underwent surgery was $40 \%$ which is comparable to that of patients candidate to immediate hepatic resection [4]. Subsequently, Adam et al. reported an update of the aforesaid data with an analysis of 701 patients; radical resection was possible in $14 \%$ of patients with a 5year survival of $35 \%$ [19]. Another important retrospective study by Giacchetti et al. analyzed 151 patients initially considered unresectable for the presence of hepatic metastases of large dimensions $(>5 \mathrm{~cm})$, multiple metastases (> 4 nodules), or metastases localized in the hepatic hilus. All patients were treated with an oxaliplatin-containing chemotherapy regimen and objective response rate was 59\%. After chemotherapy, $51 \%$ of patients were considered resectable but only $38 \%$ of patients underwent radical resection. The median survival was 48 months for the resected patients and 15.5 months for the unresected ones [20]. Recently, a study by Adam et al. evaluated long-term outcome after combining downsizing chemotherapy and rescue surgery to define prognostic factors of cure. All patients with initially unresectable colorectal liver metastases who underwent rescue surgery and had a minimum follow-up of 5 years were included. Cure was defined as a disease-free interval $>$ or $=5$ years from last hepatic or extrahepatic resection until last follow-up. One hundred eighty-four patients who underwent resection from 1988 to 2002 were evaluated. Patients had a mean number of 5.3 metastases (bilobar in 76\%), associated to extrahepatic disease in $27 \%$. Surgery was possible after one $(74 \%)$ or more $(26 \%)$ lines of chemotherapy. Five- and 10-year overall survival rates were $33 \%$ and $27 \%$, respectively. Of 148 patients with a follow-up > or $=5$ years, 24 patients (16\%) were considered cured (mean follow-up, 118.6 months), six (25\%) of whom were considered cured after resection of recurrence. Cured patients more often had three or fewer metastases less than $30 \mathrm{~mm}$ $(\mathrm{P}=0.03)$ responding to first-line chemotherapy $(\mathrm{P}=0.05)$. Multivariate analysis identified maximum size of metastases less than $30 \mathrm{~mm}$ at diagnosis, three or fewer metastases at hepatectomy, and complete pathologic response as independent predictors of cure [21]. Although these retrospective studies highlight the suitability of an integrated approach for treatment of hepatic metastases from CRC, they clearly suffer from their intrinsic limitations. 


\section{Prospective studies}

Recently some small prospective studies specifically dealing with the neoadjuvant approach in unresectable hepatic metastases from CRC have been published (Table 2) [22-24]. Alberts et al. have evaluated 42 patients treated with FOLFOX-4 reporting a $62 \%$ OR rate, a 33\% of hepatic resections and a median survival of 31.4 months in resected patients [21]. In another study, Quenet et al. have evaluated 34 patients treated with a chemotherapy regimen containing three drugs, namely OXA, IRI and 5-FU, obtaining resection of hepatic disease in $37,5 \%$ of patients [23]. Pozzo et al. treated 40 patients with FOLFIRI, obtaining an objective response in $47,5 \%$ of patients and resection of hepatic metastases in $27.5 \%$ of patients. The median survival of resected patients had not yet been reached after a median follow-up of 30.4 months [24]. Moreover, an important study by Benoist et al. analyzed 38 patients derived from a prospective monoinstitutional series of 586 consecutive patients treated for hepatic metastases from CRC. The authors' policy was to perform liver resection, including the sites of the disappeared liver metastases in patients with resectable metastases. In initially unresectable patients, resection or local ablation of all visible liver metastases was performed, leaving the disappeared liver metastases in the remnant liver. Of the 38 patients, 22 had unresectable liver metastases (multiple bilobar deposits in 20 patients and invasion of major liver vessels in 2 patients) while 16 patients had resectable disease. Complete radiological remission (cRR) was confirmed by liver examination and US during surgery in 15 patients who had initially resectable disease. However, pathologic examination of the cRR resected areas showed the presence of viable tumour cells in 12 patients (80\%). Recurrence was observed 1 year after liver resection in 10 patients (66.6\%). After 1 year, 14 of 15 patients were alive. In initially unresectable metastases liver examination and intraoperative US confirmed that there were no remaining visible tumour at the site of 31 liver metastases that had a cRR; these lesions were not resected. At 1 year, 23 patients (73\%) developed recurrences at the site of the unresected lesions [25]. The study of Benoist et al showed that although radiological complete response may be a useful criterion for evaluating the efficacy of chemotherapy, it does not mean a potential cure. In fact, the study indicated that the planned curative resection should not be altered by radiographic responses and that a cRR in a lesion that cannot be resected because of its anatomic site affects the potential for surgical cure. In fact, viable cancer cells are still present in liver even if a cRR is documented by US and CT and are responsible of 
in situ relapse in disappeared areas. Pathologic complete response remains the goal of the neoadjuvant treatment. In light of these data, systemic chemotherapy with neoadjuvant intent in patients with initially unresectable liver metastases from CRC seems a potential curable option However, many questions remain unanswered: which is the optimal neoadjuvant regimen and how many cycles are more appropriate before surgery? The planned curative resection should be determined by radiogralogical response? Does the response to neoadjuvant chemotherapy indicate the continuation of the same therapy after surgery? We have no definitive answers to these questions. For these reasons, all patients with initially unresectable liver metastases from CRC should always be addressed by a multidisciplinary team to determine the best treatment plan.

\section{Neoadjuvant chemotherapy in resectable liver metastasis: is it worthwhile?}

Feasibility and effectiveness of neoadjuvant chemotherapeutic treatment in patients with initially resectable hepatic metastases is still debated. Perioperative morbidity after neoadjuvant treatment of liver metastases is a major issue, especially in patients with resectable disease. Several reports have recently raised the issue of the potential liver toxicity of pre-operative chemotherapy. To date a long-term control of benefits (i.e. disease free survival and overall survival) has not been carried out. Thus, all patients with resectable liver metastasis eligible for neoadjuvant chemotherapy require accurate risk/benefit evaluation. Gruenberger et al have evaluated 50 patients with resectable hepatic metastases ( 1 metastasis 30\%; 2-3 metastasis 22\%; > 4 metastases $48 \%$ ) treated with a neoadjuvant regimen containing oxaliplatin (30 patients with XELOX, 20 patients with FOLFOX4). All patients underwent surgery and obtained hepatic resection R0, with no surgery-related deaths and a morbidity of $12 \%$. At a preliminary follow-up, 58\% of patients were diseasefree, $20 \%$ had relapsed and $22 \%$ had died [26]. In another study Taieb et al. studied 22 patients with resectable hepatic metastases treated with neoadjuvant chemotherapy according to the FOLFOX7 regimen. Twenty patients (91\%) obtained R0 hepatic resection [27]. Recently, feasibility and efficacy data of the phase III EORTC 40983 study have been reported. The study compared perioperative chemotherapy with Folfox regimen (six cycles before surgery and six cycles after) with surgery alone in 364 patients and 
showed that Folfox does not affect the mortality of hepatectomy for resectable colo-rectal liver metastases. Reversible post-operative complications occurred more often after chemotherapy than after surgery (25\% vs $16 \% ; \mathrm{p}=0.04)$. The rate of progression-free-survival at 3 years increased from $33.2 \%$ to $42.4 \%$ in the chemotherapy group, with an absolute increase in rate of progression-free survival at 3 years of $9.2 \%$ in patients undergoing resection [8]. This trial indicated that perioperative chemotherapy with Folfox is compatible with major liver surgery and reduces the risk of progression-free survival in resected patients. Characteristic of results of neoadjuvant chemotherapy trials with resectable liver metastases are detailed in Table 3. On the other hand, there is accumulated data of specific hepatic toxicities in patients treated with neoadiuvant chemotherapy before liver surgery. Specifically, two main types of liver damage have been reported: vascular changes and chemotherapy-associated steatohepatitis (CASH) [28-30]. Vauthey et al. analyzed the effects of preoperative fluoropyrimidine-based regimens (5-FU alone, irinotecan plus 5-FU, oxaliplatin plus 5-FU) on liver histology in 248 patients compared to 158 patients who did not receive preoperative chemotherapy. Oxaliplatin was associated with sinusoidal dilation (18.9\% oxaliplatin vs $1.9 \%$ no chemotherapy, $\mathrm{p}<0.001$; odds ratio $=8.3)$ while irinotecan was associated with steatohepatitis $(20.2 \%$ irinotecan vs $4.4 \%$ no chemotherapy, $\mathrm{p}<0.001$; odds ratio $=5.4)$. It is noteworthy that steatohepatitis was associated with increased 90-day mortality after hepatic surgery compared to patients who did not have steatohepatitis $(14.7 \%$ vs. $1.6 \%$, respectively; $p=0.001$; odds ratio $=10.5)$, while vascular changes increased the risk of operative bleeding but not that of perioperative morbidity or mortality [28]. Fernandez et al studied the presence of non-alcoholic steatohepatitis (NASH) in 37 patients who underwent hepatic resection of CRC metastases. Thirteen patients received no neoadjuvant therapy, 10 received 5-fluorouracil only, and 14 received neoadjuvant irinotecan $(n=12)$, or oxaliplatin, or both $(n=4)$, in conjunction with 5-FU. A multivariate analysis showed that both irinotecan or oxaliplatin-based regimens and body mass index were independent risk factors for developing steatohepatitis [29]. Adam et al. reported results from a retrospective analysis in 92 patients who had liver resection for CRC hepatic metastases treated without (17 pts) and with chemotherapy based on 5-FU alone (23 pts) or associated with oxaliplatin (52 pts). Vascular changes were more frequent in the group treated with chemotherapy $(52 \mathrm{vs} 18 \%, \mathrm{p}<0.01)$. There was also a trend towards a higher incidence of fibrosis and centrolobular necrosis (CLN) in the chemotherapy group. FOLFOXtreated patients had less steatosis and fibrosis, equal sinusoidal changes but more CLN (35 vs 4\%, p=0.07) 
than 5-FU alone. The outcome of patients following liver resection was not affected by these histological changes.. However, prolonged preoperative chemotherapy (>12 cycles) was related to a longer duration of hospital stay (15 vs. 11 days, respectively; $\mathrm{p}=0.02)$ and was a risk factor for re-operation (11\% vs. $0 \%$, respectively; $\mathrm{p}=0.04)$ [30]. Regenerative nodular hyperplasia $(\mathrm{RNH})$ represents the worst evolutive stage of vascular lesions induced by chemotherapy in the liver. In a recent retrospective analysis conducted upon 107 patients, Whichert et al. evaluated the impact of RNH on postoperative morbidity. As result, patients who received prolonged courses of preoperative Oxaliplatin had an increased risk of RHN and associated postoperative hepatic morbidity (23\% vs $11 \%$ observed in Oxaliplatin naive patients). Moreover, preoperative gamma-glutamil-transferase $(\mathrm{GGT})>30 \mathrm{U} / \mathrm{L}$ and a total bilirubin level $>15 \mu \mathrm{mol} / \mathrm{L}$ resulted to be independent predictive factors of RHN development [31].

As a result of the above data, patients with resectable metastasis should be considered for neoadjuvant chemotherapy, but patients should not be overtreated to avoid chronic and progressive chemotherapyinduced liver damage, which could preclude curative surgery. Some liver injury predictive factors are emerging from literature [32], but a more reliable assessment remains an important area of clinical investigation. Furthermore, considering the lack of data on neoadjuvant chemotherapy in terms of overall survival, we do not know if benefits of pre-operative chemotherapy encompass the risk of potential liver toxicities in patients with initially resectable liver metastases. In this regard, the recent EORTC 40983 trial data seem to tilt the balance towards the benefits of pre-operative chemotherapy. Further clinical studies are warranted in this setting.

\section{Neoadjuvant chemotherapy: increasing appeal with the introduction of biologic agents?}

Recent studies have shown the remarkable therapeutic effectiveness of some biological agents in advanced CRC. In particular, bevacizumab, a monoclonal antibody anti-vascular endothelial growth factor (VEGF) and cetuximab, a monoclonal antibody anti-epidermal growth factor receptor (EGFR), are the most interesting molecules. They have evidenced important therapeutic properties and are leading to a dramatic change of the therapeutic standards in advanced CRC [33-35]. In the most impressive study, Hurwitz et al. 
randomized 813 patients with metastatic CRC receiving either the combination of IFL and bevacizumab or IFL alone. A significant advantage of IFL plus bevacizumab compared to IFL alone was reported in terms of OR (44,8 vs. $34.8 ; \mathrm{p}=0.004)$ and median survival (20,3 vs. 15,6 months; $\mathrm{p}=0.001)$ [33]. Analogous results have also been obtained in a study in which bevacizumab was associated either with 5-FU/LV or with FOLFOX in the second-line treatment of metastatic disease [34,35]. It has been demonstrated that the association of standard drugs with bevacizumab in first-line and second-line treatment significantly increases the percentage of OR and the overall survival. Moreover, many studies indicate that bevacizumab does not increase toxicity correlated to chemotherapy, while bevacizumab-specific side effect are reported, such as proteinuria, hypertension, bleeding, wound healing delay, arterial thrombosis and gastrointestinal perforation [36-38]. The use of bevacizumab in the neoadjuvant setting may be associated with major adverse events, such as wound healing delays, bleeding and defects in liver regeneration at the time of surgery. Clinical trials of bevacizumab in metastatic colorectal cancer reported $10 \%$ of patients having wound healing complication after major unplanned or elective surgery while on therapy [38]. The main issue is the interval between neoadjuvant bevacizumab and hepatic resection. The first BEAT study was aimed at evaluating the safety of bevacizumab in a broader patient population using a variety of chemotherapy regimens, such as FOLFOX, CAPOX, FOLFIRI. The trial design mandated BEV to be stopped at least 6-8 weeks before metastasectomy; when appropriate BEV was restarted 28 days after surgery. 1927 patients were enrolled in the study; 63 had undergone metastectomy and 60 had liver resections. Median time from last BEV administration to surgery was 56 days and median follow-up was 15.4 months. Chemotherapy regimens used with BEV included FOLFOX (n=24), XELOX ( $n=16)$, and FOLFIRI $(n=15)$. No wound healing delay or bleeding related to surgery was reported; $70 \%$ of patients reported no complications. One patient had concomitant myocardial infarction and portal vein thrombosis, possibly related to BEV therapy [39].

In NO16966 trial patients with metastatic colorectal cancer were randomly assigned to XELOX versus FOLFOX-4, and then to bevacizumab versus placebo. The primary end point progression-free survival (PFS) was reached because bevacizumab had a significant effect on PFS (9,4 months versus 8,0 months, $\mathrm{P}=0.0023)$. Interestingly, 44/699 (6.3\%) patients receiving BEV underwent R0 resection compared with 34/701 (4.9\%) patients receiving placebo $(\mathrm{p}=\mathrm{NS})$. Median overall survival was 21.3 months in the 
bevacizumab group and 19.9 months in the placebo group (HR, 0.89; $97.5 \% \mathrm{CI}, 0.76$ to $1.03 ; \mathrm{P}=.077)$. Response rates were similar in both arms. [40]. Recently, Gruenberger et al. have reported the results of a single-center, phase II study designed to determine the feasibility, perioperative complication rate and potential impact on post-operative liver regeneration with neoadjuvant capecitabine and oxaliplatin (Xelox) plus bevacizumab in patients with potentially curable liver metastases. Fifty-six patients were accrued and objective response to neoadjuvant chemotherapy was observed in 41 patients (73\%). Fifty-two patients underwent liver resection and no increased intraoperative bleeding events or wound-healing complications were observed. No postoperative mortality occurred and morbidity was encountered in 11 patients (20\%). This trial demonstrated that in patients who received bevacizumab up to 5 weeks before liver resection, the rate of surgical, wound healing or bleeding complications were not increased compared with historical data for chemotherapy alone.[39]. Much more recently, Bouganim et al. carried out a retrospective analysis upon 60 patients treated with preoperative chemoterapy containing bevacizumab. Response was observed in $80 \%$ of patients. Overall survival rates at 12, 24, 36 and 48 months were, $100 \%, 86 \%, 74 \%$ and $66 \%$, respectively. Median progression free survival was 14 months (13 in Irinotecan receiving population and 15 in Oxaliplatin group). No sudden death or bowel perforation were reported [41]. Additionally, in another recent study, resected liver specimens from patients in two prospective, non-randomized trials (5fluorouracil/oxaliplatin+/-bevacizumab) were analyzed retrospectively. Interestingly, bevacizumab decreased the severity of the sinusoidal obstruction syndrome and had no impact on hepatic steatosis and fibrosis. This analysis showed that bevacizumab could protect against the sinusoidal obstruction syndrome and provide the histological explanation for the safe use of bevacizumab prior to liver resection [42].

Cetuximab, a chimeric monoclonal antibody targeting EGFR, has shown high activity in advanced colorectal cancer either alone or in combination and does not increase complications in surgery. Cetuximab has the advantage of a shorter half-life (10 days) with respect to bevacizumab; furthermore, there is no current evidence that EGFR-targeted drugs may affect wound healing and liver regeneration. Moreover, the favourable response rates observed in advanced disease suggest that liver metastases could be effectively downsized, thus rendering the drug potentially appealing in the neoadjuvant setting. To date, only one study specifically exploring the role of cetuximab therapy on resectability of colorectal cancer liver 
metastases has been published. The study was performed to determine the post-cetuximab resectability rate and to examine postoperative outcomes in a group of heavily pretreated patients. One hundred fifty-one patients with unresectable CLM resistant to initial chemotherapy and subsequently treated with systemic cetuximab were evaluated. Twenty-seven patients underwent surgery after a median of six cycles of cetuximab + irinotecan (20 of 27), oxaliplatin (four of 27), or both (one of 27). Eighteen patients (67\%) had experienced treatment failure after at least two lines of chemotherapy before cetuximab. Twenty-five of the 27 patients who had surgery underwent hepatectomy. Postoperative mortality was $3.7 \%$ (one of 27), with a complication rate of 50\%. Histopathologic liver abnormalities were found in nine patients (36\%), without specific lesions attributable to cetuximab. After median follow-up of 16 months, 23 of 25 patients who underwent resection (92\%) were alive, and 10 patients (40\%) were disease free. Median overall (OS) and progression-free survival (PFS) from initiation of cetuximab therapy were 20 and 13 months, respectively. Thus, combination therapy with cetuximab increased resectability rates without increasing operative mortality or liver injury suggesting that this strategy benefits patients with previously refractory disease who respond subsequently to cetuximab. [43] Recently, preliminary data from a randomized phase II study of cetuximab plus FOLFOX6 or FOLFIRI (CELIM study, ASCO, 2009 Gastrointestinal Cancers Symposium, Abs. 296) demonstrated high response rates (85\% and 66\%, respectively) in neoadjuvant therapy of unresectable colorectal liver metastases. Forty percent of FOLFOX6 plus cetuximab patients underwent resection (37\% R0), compared with 43\% (35\% R0) of FOLFIRI plus cetuximab patients and 43\% (34\% R0) of patients with KRAS wild-type tumors. In a combined analysis of both arms, the 67 patients with wild-type KRAS tumors achieved a response rate of 79\%. [44]. Furthermore, interesting data are emerging from phase III studies non specifically designed for patients with liver metastases. Impressive improvement of the resectability rate in patients with initially unresectable liver metastases treated with cetuximab in association with both FOLFOX and FOLFIRI regimens has been observed.

In the CRYSTAL study the efficacy of cetuximab plus irinotecan, fluorouracil, and leucovorin (FOLFIRI) as first-line treatment for metastatic colorectal cancer was investigated. A total of 599 patients received cetuximab plus FOLFIRI, and 599 received FOLFIRI alone with a randomization procedure. The hazard ratio for progression free survival in the cetuximab-FOLFIRI group as compared with the FOLFIRI group 
was $0.85(95 \%$ confidence interval $[\mathrm{CI}], 0.72$ to $0.99 ; \mathrm{P}=0.048)$. There was no significant difference in the overall survival between the two treatment groups (hazard ratio, $0.93 ; 95 \% \mathrm{CI}, 0.81$ to $1.07 ; \mathrm{P}=0.31$ ). KRAS mutation was predictive of response $(\mathrm{P}=0.03)$ but not of progression-free survival $(\mathrm{P}=0.07)$ or overall survival $(\mathrm{P}=0.44)$. Interestingly, the rate of surgery for metastases was higher in the cetuximabFOLFIRI group than in the FOLFIRI group (7.0\% vs. 3.7\%), as was the rate of R0 resection with curative intent before disease progression (4.8\% vs. $1.7 \%$; odds ratio for cetuximab-FOLFIRI, 3.02; $95 \%$ CI, 1.45 to $6.27 ; \mathrm{P}=0.002)$. With regard to only liver-confined disease, a rate of curative liver resection was achieved in $4.5 \%$ for FOLFIRI alone vs $9.8 \%$ for cetuximab-FOLFIRI [45]. In the OPUS study, patients were randomized to cetuximab plus FOLFOX-4 $(n=169)$ or FOLFOX-4 alone $(n=168)$ as first-line treatment for metastatic disease. The ORR for cetuximab plus FOLFOX-4 was higher than with FOLFOX-4 alone (46\% $v$ $36 \%$ ). In patients with KRAS wild-type tumors, the addition of cetuximab to FOLFOX-4 was associated with a clinically significant increased chance of response $(\mathrm{ORR}=61 \% v 37 \%$; odds ratio $=2.54 ; P=.011)$ and a lower risk of disease progression (hazard ratio $=0.57 ; P=.0163$ ) compared with FOLFOX-4 alone. The addition of cetuximab to FOLFOX-4 was associated with an approximate doubling of the R0 resection rate from $2.4 \%$ (four of 168 patients) for FOLFOX-4 alone to $4.7 \%$ (eight of 169 patients) for cetuximab plus FOLFOX-4. [46]. Garufi et al. tested the combination of cetuximab, Irinotecan, Oxaliplatin, 5FU and Folinic Acid followed by surgery in 45 patients with unresectable colorectal liver metastasis and an encouraging $63 \%$ complete resection rate was achieved [47].

In conclusion, these data prompt the use of biologic agents in the neoadjuvant setting and open a real opportunity for pursuing curative resection also in patients with initially unresectable liver metastases. Both cetuximab and bevacizumab appear equally effective in combination with chemotherapy. The addition of cetuximab should be preferred in patients with wild-type KRAS tumors. Data from CRYSTAL and OPUS are pooled from subgroup analysis within large phase III studies in the metastatic setting and thus, they suffer of statistical pitfalls. Prospective, ad hoc trials are warranted in the near future in order to assess the effective role of biologic agents in the neoadjuvant setting and establish which targeted agent is the preferred combination partner for specific chemotherapy. 


\section{Conclusions}

The addition of biological agents to chemotherapy, such as bevacizumab and cetuximab, and the improvements of surgical techniques have opened a new scenario in the management of colorectal liver metastases. For many years, the diagnosis of liver metastases from CRC was characterized by a dismal prognosis. Chemotherapy and surgery were two worlds which ignored each other. Recently, the EORTC trial has demonstrated that perioperative chemotherapy (Folfox regimen) is feasible and improves progression free survival in patients with resectable liver metatsases. Chemotherapy and surgery can finally work together. In the unresectable setting the association of chemotherapy with bevacizumab and cetuximab is particularly promising in improving resectability rate. In particular, K-RAS is a molecular response predictive factor that could be particularly useful in selecting the best treatment option in patients with unresectable liver disease.

Challenges for the immediate future are represented by: the definition of the role of biological agents as neoadjuvants, the assessment of biological markers of response to pre-operative chemotherapy, and the assessment of the best chemotherapy liver toxicity profile. 


\section{References}

1. Bonadonna G, Robustelli della Cuna G, Valagussa P (2009) Medicina Oncologica VII

2. Jemal A, Tiwari RC, Murray T, Ghafoor A, Samuels A, Ward E et al (2004) Cancer Statistics. CA Cancer J Clin 54:8-29

3. Scheele J, Stang R, Altendorf-Hofmann A, Paul M (1995) Resection of colorectal liver metastases. World J Surg; 19:59-71

4. Bismuth H, Adam R, Lévi F, Farabos C, Waechter F, Castaing D et al (1996) Resection of nonresectable liver metastases from colorectal cancer after neoadjuvant chemotherapy. Ann Surg 224:509-522

5. Adson MA (1987) Resection of liver metastases: when is it worthwhile? World J Surg 11:511520

6. Fong Y, Cohen AM, Fortner JG, Enker WE, Turnbull AD, Coit DG et al (1997) Liver resection for colorectal metastases. J Clin Oncol 15:938-946

7. Kato T, Yasui K, Hirai T, Kanemitsu Y, Mori T, Sugihara K et al (2003) Therapeutic results of hepatic metastases of colorectal cancer with special reference to effectiveness of hepatectomy: Analysis of prognostic factors for 763 cases recorded at 18 institutions. Dis Colon Rectum 46:22-31

8. Nordlinger B, Sorbye H, Glimelius B, Poston GJ, Schlag PM, Rougier P et al (2008) Perioperative chemotherapy with FOLFOX4 and surgery versus surgery alone for resectable liver metastases from colorectal cancer (EORTC Intergroup trial 40983): a randomised controlled trial. Lancet 371:1007-1016

9. Ekberg H, Tranberg KG, Andersson R, Lundstedt C, Hägerstrand I, Ranstam J et al (1986) Determinants of survival in liver resection for colorectal secondaries. Br J Surg 73:727-731

10. Poston G, Haller D, Kahan J, Cornelis M, Mahyaoui S (2004) Individualize the treatment of liver metastases from colorectal cancer using RAND appropriateness method: Oncosurge decision model-Results of a consensus detecting from the international task force group. J Clin Oncol 22:abstr 3595 
11. Nordlinger B, Guiguet M, Vaillant JC, Balladur P, Boudjema K, Bachellier P et al (1996) Surgical resection of colorectal carcinoma metastases to the liver : A prognostic scoring system to improve case selection, based on 1568 patients. Cancer 77:1254-1262

12. Iwatsuki S, Dvorchik I, Madariaga JR, Marsh JW, Dodson F, Bonham AC et al (1999) Hepatic resection for metastatic colorectal adenocarcinoma: A proposal of a prognostic scoring system. $\mathrm{J}$ Am Coll Surg 189:291-299

13. Adam, V. Delvart, G. Pascal, D. Castaing, D. Azoulay, S. Giachetti, B et al (2004) Resection of non resectable liver metastases after chemotherapy: Prognostic factors and long-term results. J Clin Oncol 22:abstr 3550

14. Mala T, Bohler G, Mathisen O, Bergan A, Søreide O (2002) Hepatic resection for colorectal metastases: Can preoperative scoring predict patient outcome? World J Surg; 26:1348-1353

15. Quispe IR, F. Ramos J, Bilbao I, Macarulla T, Cedres S, Charco R et al (2009) Long-term overall survival (os) and prognostic factors of patients (pts) with surgery of liver metastases from colorectal cancer origin $(1 \mathrm{~m} / \mathrm{crc})$ : Retrospective analysis of a Spanish single institution. J Clin Oncol 27:abstr 15052

16. Tournigand C, André T, Achille E, Lledo G, Flesh M, Mery-Mignard D et al (2004) FOLFIRI followed by FOLFOX6 or the reverse sequence in advanced colorectal cancer: A randomised GERCOR study. J Clin Oncol 22:229-237

17. Goldberg RM, Sargent DJ, Morton RF, Fuchs CS, Ramanathan RK, Williamson SK et al (2004) A randomised controlled trial of fluorouracil plus leucovorin, irinotecan, and oxaliplatin combinations in patients with previously untreated metastatic colorectal cancer. J Clin Oncol 22:23-30

18. Falcone A, Ricci S, Brunett I, Pfanner E, Allegrini G, Barbara C et al (2007) Phase III Trial of Infusional Fluorouracil, Leucovorin, Oxaliplatin, and Irinotecan (FOLFOXIRI) Compared With Infusional Fluorouracil, Leucovorin, and Irinotecan (FOLFIRI) As First-Line Treatment for Metastatic Colorectal Cancer: The Gruppo Oncologico Nord Ovest. J Clin Oncol 25:1670-1676

19. Adam R, Avisar E, Ariche A, Giachetti S, Azoulay D, Castaing D, et al. Five-year survival following hepatic resection after neoadjuvant therapy for nonresectable colorectal (liver) metastases. Ann Surg Oncol 2001; 8: 347-53.

20. Giacchetti S, Itzhaki M, Gruia G, Adam R, Zidani R, Kunstlinger F et al (1999) Long-term survival of patients with unresectable colorectal cancer liver metastases following infusional chemotherapy with 5-fluorouracil, leucovorin, oxaliplatin and surgery. Ann Oncol 10:663-669

21. Adam R, Wicherts DA, de Haas RJ, Ciacio O, Lévi F, Paule B et al (2009) Patients With Initially Unresectable Colorectal Liver Metastases: Is There a Possibility of Cure? J Clin Oncol 27:1829-1835

22. Alberts SR, Donohue JH, Mahoney MR, Horvath WL, Sternfeld WC, Dakhil SR et al (2003) Liver resection after 5-fluorouracil, leucovorin and oxaliplatin for patients with metastatic colorectal cancer (MCRC) limited to the liver: A North Central Cancer Treatment Group (NCCTG) phase II study. J Clin Oncol 22:abstr 1053 
23. Quenet F, Nordlinger B, Rivoire M, Delpero JR, Portier G, Mery-Mignard D et al (2004) Resection of previously unresectable liver metastases from colorectal cancer (LMCRC) afer chemotherapy (CT) with CPT-11/L-OHP/LV5FU (Folfirinox): A prospective phase II trial. J Clin Oncol 22:abstr 3613

24. Pozzo C, Basso M, Cassano A, Quirino M, Schinzari G, Trigila N et al (2004) Neoadjuvant treatment of unresectable liver disease with irinotecan and 5-fluorouracil plus folinic acid in colorectal cancer patients. Ann Oncol 15:933-939

25. Benoist S, Brouquet A, Penna C, Julie C, El Hajjam M, Chagnon S et al (2006) Complete response of colorectal liver metastases after chemotherapy: does it mean cure? J Clin Oncol 24:3939-3945.

26. Gruenberger T, Schuell B, Kornek G, Scheithauer W (2004) Neoadjuvant chemotherapy for resectable colorectal cancer liver metastasis: Impact on magnitude of liver resection and survival. J Clin Oncol 22: abstr 3598

27. Taïeb J, Artru P, Paye F, Louvet C, Perez N, André T et al (2005) Intensive systemic chemotherapy combined with surgery for metastatic colorectal cancer : results of a phase II study. J Clin Oncol 23:502-509

28. Vauthey JN, Pawlik TM, Ribero D, Wu TT, Zorzi D, Hoff PM et al (2006) Chemotherapy regimen predicts steatohepatitis and an increase in 90-day mortality after surgery for hepatic colorectal metastases. J Clin Oncol 24:2065-2072

29. Fernandez FG, Ritter J, Goodwin JW, Linehan DC, Hawkins WG, Strasberg SM (2005) Effect of steatohepatitis associated with irinotecan or oxaliplatin pretreatment on resectability of hepatic colorectal metastases. J Am Coll Surg 200: 845-853

30. Adam R, Sebagh M, Plasse M, Karam V, Giachetti S, Azoulay D, et al (2005) Impact of preoperative systemic chemotherapy on liver histology and outcome of hepatic resection for colorectal cancer liver metastases (CRLM). J Clin Oncol 23:abstr 3529

31. Wicherts DA, De Haas RJ, Sebagh M, Ciacio O, Lévi F, Paule B et al (2009) Liver regenerative nodular hyperplasia consecutive to preoperative chemotherapy: Impact on outcome of liver surgery for colorectal metastases. J Clin Oncol 27:abstr 4097

32. Nordlinger B, Benoist S. Benefits and risks of neoadjuvant therapy for liver metastases (2006) J Clin Oncol 24:4954-4955

33. Hurwitz H, Fehrenbacher L, Novotny W, Cartwright T, Hainsworth J, Heim W et al (2004) Bevacizumab plus irinotecan, fluorouracil, and leucovorin for metastatic colorectal cancer. $\mathrm{N}$ Engl J Med 350:2335-2342

34. Kabbinavar FF, Hambleton J, Mass RD, Hurwitz HI, Bergsland E, Sarkar S (2005) Combined analysis of efficacy: the addition of Bevacizumab to fluorouracil/leucovorin improves survival for patients with metastatic colorectal cancer. J Clin Oncol 23:3706-3712

35. Giantonio BJ, Catalano PJ, Meropol NJ, Mitchell EP, Schwartz MA, Alberts SR et al (2007) Bevacizumab in combination with oxaliplatin, fluorouracil, and leucovorin (FOLFOX4) for 
previously treated metastatic colorectal cancer: results from the Eastern Cooperative Oncology Group Study E3200. J Clin Oncol 25:1539-1544

36. Scappaticci FA, Fehrenbacher L, Cartwright T, Hainsworth JD, Heim W, Berlin J et al (2005) Surgical wound healing complications in metastatic colorectal cancer patients treated with bevacizumab. J Surg Oncol 91:173-180

37. Ellis LM, Curley SA, Grothey A (2005) Surgical resection after downsizing of colorectal liver metastases in the era of bevacizumab. J Clin Oncol 23:4853-4855

38. Gruenberger B, Tamandl D, Schueller J, Scheithauer W, Zielinski C, Herbst F et al (2008) Bevacizumab, Capecitabine, and Oxaliplatin as neoadjuvant therapy for patients with potentially curable metatsatic colorectal cancer. J Clin Oncol 26:1830-1835

39. Michael M, Van Cutsem E, Kretzschmar A, Berry S, Rivera F, Dibartolomeo M et al (2006) Feasibility of metastasectomy in patients treated with bevacizumab in first-line mCRC: Preliminary results from the First Beat-study. J Clin Oncol 24:abstr 3523

40. Saltz LB, Clarke S, Díaz-Rubio E, Scheithauer W, Figer A, Wong R et al (2008) Bevacizumab in Combination With Oxaliplatin-Based Chemotherapy As First-Line Therapy in Metastatic Colorectal Cancer: A Randomized Phase III Study. J Clin Oncol 26:2013-2019

41. N. Bouganim, P. Kavan, M. Eid, P. Metrakos, P. Chaudhury, G. Batist (2009) Perioperative chemotherapy with bevacizumab (BV) for liver metastases (LM) in colorectal cancer (CRC): McGill University pilot study. J Clin Oncol abstr e15027

42. Klinger M, Eipeldauer S, Hacker S, Herberger B, Tamandl D, Dorfmeister M et al (2009) Bevacizumab protects against sinusoidal obstruction syndrome and does not increase response rate in neoadjuvant XELOX/FOLFOX therapy of colorectal cancer liver metastases. Eur J Surg Oncol 35:515-520

43. Adam R, Aloia T, Lévi F, Wicherts DA, de Haas RJ, Paule B et al (2007) Hepatic resection after rescue cetuximab treatment for colorectal liver metastases previously refractory to conventional systemic therapy. J Clin Oncol 25: 4593-4602

44. Folprecht G, Gruenberger T, Hartmann JT et al (2008) Randomized multicenter study of cetuximab plus FOLFIRI in neoadjuvant treatment of non-resectable colorectal liver metastases (CLM). Ann Oncol abstr 510PD.

45. Van Cutsem E, Köhne CH, Hitre E, Zaluski J, Chang Chien CR, Makhson A et al (2009) Cetuximab and chemotherapy as initial treatment for metastatic colorectal cancer. N Engl J Med 360:1408-1417

46. Bokemeyer C, Bondarenko I, Makhson A, Hartmann JT, Aparicio J, de Braud F et al (2009) Fluorouracil, leucovorin, and oxaliplatin with and without cetuximab in the first-line treatment of metastatic colorectal cancer. J Clin Oncol 27: 663-671

47. Garufi C, Torsello A, Tumolo S, Mottolese M, Campanella C, Zeuli M et al (2009) POCHER (preoperative chemotherapy for hepatic resection) with cetuximab (Cmab) plus CPT-11/5fluorouracil (5FU)/leucovorin(FA)/oxaliplatin (L-OHP) (CPT-11-FFL) in unresectable colorectal liver metastases (CLM). J Clin Oncol abstr e15020 
Table 1: Controindications for the hepatic resection of colorectal cancer metastases:

\section{Before consensus:}

$>4$ metastases

Extrahepatic disease 


Resection margins $<1 \mathrm{~cm}$
Multinodular metastasis
Ilar metastases
After consensus:
Cancer in more than $50 \%$ of parenchyma or six segments
Extra-hepatic disease
Unfit patients
Factors included in clinical scoring systems:
Positive lymphnodes
Disease-free survival $<12$ months
More than a tumor
Elevated preoperative CEA

Table 2. Characteristics and results of neoadjuvant chemotherapy including patients with unresectable liver metastases from colorectal cancer.

\begin{tabular}{|c|c|c|c|c|c|c|c|c|}
\hline $\begin{array}{c}\text { Author } \\
\text { (year) }\end{array}$ & Therapy & $\begin{array}{c}\text { Phas } \\
\text { e }\end{array}$ & $\begin{array}{c}\text { n. } \\
\text { patient } \\
\text { s }\end{array}$ & $\begin{array}{c}\text { Prospectiv } \\
\mathbf{e}\end{array}$ & $\begin{array}{c}\text { Specificall } \\
\text { y designed }\end{array}$ & OR rate & $\begin{array}{c}\text { Survival } \\
\text { (\% or } \\
\text { median) }\end{array}$ & $\begin{array}{c}\text { \% } \\
\text { resectabilit } \\
\mathbf{y}\end{array}$ \\
\hline $\begin{array}{c}\text { Bismuth et } \\
\text { al (1996) }\end{array}$ & $\begin{array}{c}\text { FU/FA/oxa } \\
\text { cronomodulate } \\
\text { d }\end{array}$ & II & 53 & No & No & NR & $\begin{array}{c}40 \% \text { at } 5 \\
\text { years }\end{array}$ & 16 \\
\hline
\end{tabular}




\begin{tabular}{|c|c|c|c|c|c|c|c|c|}
\hline $\begin{array}{l}\text { Giacchetti } \\
\text { et al } \\
\text { (1999) }\end{array}$ & $\begin{array}{c}\text { OXA } \\
\text { containing } \\
\text { regimens }\end{array}$ & II & 151 & No & No & $59 \%$ & $48 \mathrm{~m}$ & 38 \\
\hline $\begin{array}{l}\text { Adam et al } \\
2001\end{array}$ & $\begin{array}{c}\text { FU/FA/OXA } \\
\text { cronomodulate } \\
\text { d }\end{array}$ & II & 95 & No & No & $\begin{array}{c}\text { cCR:4/9 } \\
5 \\
\text { pCR: } 6 / 9 \\
5\end{array}$ & $\begin{array}{c}35 \% \text { at } 5 \\
\text { years }\end{array}$ & 14 \\
\hline $\begin{array}{l}\text { Alberts et } \\
\text { al } 2003\end{array}$ & FOLFOX4 & II & 42 & Yes & Yes & $62 \%$ & $31.4 \mathrm{~m}$ & 33 \\
\hline $\begin{array}{c}\text { Tournigan } \\
\text { d et al } \\
(2004) \\
\end{array}$ & $\begin{array}{c}\text { FOLFOX6 } \\
\text { FOLFIRI }\end{array}$ & III & 220 & No & No & $\begin{array}{l}54 \% \\
56 \%\end{array}$ & $\begin{array}{l}20.6 \mathrm{~m} \\
21.5 \mathrm{~m}\end{array}$ & $\begin{array}{c}13 \\
7\end{array}$ \\
\hline $\begin{array}{l}\text { Goldberg } \\
\text { et al. } \\
(2004)\end{array}$ & $\begin{array}{c}\text { FOLFOX } \\
\text { IFL } \\
\text { IROX } \\
\end{array}$ & III & 795 & No & No & $\begin{array}{l}45 \% \\
31 \% \\
35 \% \\
\end{array}$ & $\begin{array}{l}19.5 \mathrm{~m} \\
15.0 \mathrm{~m} \\
17.4 \mathrm{~m} \\
\end{array}$ & $\begin{array}{l}4.1 \\
0.75\end{array}$ \\
\hline $\begin{array}{l}\text { Quenet et } \\
\text { al. (2004) }\end{array}$ & FU/OXA/IRI & II & 34 & Yes & Yes & $72 \%$ & NR & 37.5 \\
\hline $\begin{array}{l}\text { Pozzo et } \\
\text { al. (2004) }\end{array}$ & FOLFIRI & II & 40 & Yes & Yes & $47.5 \%$ & $\begin{array}{c}\text { not } \\
\text { reached } \\
\text { after } 30.4 \\
\text { m }\end{array}$ & 27.5 \\
\hline $\begin{array}{l}\text { Benoist et } \\
\text { al. (2006) }\end{array}$ & $\begin{array}{c}\text { FU/FA } \\
\text { FU/FA/OXA } \\
\text { FU/FA/IRI }\end{array}$ & II & 38 & No & No & NA & $\begin{array}{c}79 \% \\
\text { recurred } \\
\text { in situ at } \\
1 \text { year }\end{array}$ & NA \\
\hline $\begin{array}{l}\text { Adam et al } \\
(2009)\end{array}$ & $\begin{array}{l}\text { Different } \\
\text { schedules }\end{array}$ & II & 184 & No & No & $62 \%$ & $\begin{array}{c}33 \% \text { at } 5- \\
\text { year }\end{array}$ & $\begin{array}{c}\text { Not } \\
\text { applicable }\end{array}$ \\
\hline $\begin{array}{c}\text { CRYSTA } \\
\text { L (2009) }\end{array}$ & $\begin{array}{l}\text { FOLFIRI vs } \\
\text { FOLFIRI plus } \\
\text { Cetuximab }\end{array}$ & III & $\begin{array}{c}599 \text { vs } \\
599\end{array}$ & Yes & No & $\begin{array}{c}39 \% \text { vs } \\
47 \% \\
\text { (All } \\
\text { patients) }\end{array}$ & $\begin{array}{c}19.9 \mathrm{~m} \\
\text { vs } 18.6 \\
\text { m }\end{array}$ & $\begin{array}{c}3.7 \% \text { vs } \\
7.0 \%\end{array}$ \\
\hline $\begin{array}{l}\text { OPUS } \\
\text { (2009) }\end{array}$ & $\begin{array}{c}\text { FOLFOX-4 vs } \\
\text { FOLFOX-4 } \\
\text { plus } \\
\text { Cetuximab }\end{array}$ & II & $\begin{array}{c}168 \text { vs } \\
169\end{array}$ & Yes & No & $\begin{array}{c}36 \% \text { vs } \\
46 \% \\
\text { (All } \\
\text { patients) }\end{array}$ & $\begin{array}{c}\text { Not } \\
\text { applicabl } \\
\mathrm{e}\end{array}$ & $\begin{array}{c}2.4 \% \text { vs } \\
4.7 \%\end{array}$ \\
\hline Celim & $\begin{array}{c}\text { FOLFOX6 } \\
\text { plus cetuximab } \\
\text { vs FOLFIRI } \\
\text { plus cetuximab }\end{array}$ & II & $\begin{array}{c}56 \text { vs } \\
55\end{array}$ & Yes & Yes & $\begin{array}{c}75 \% \text { vs } \\
79 \% \text { in } \\
\text { K-RAS } \\
\text { wt }\end{array}$ & $\begin{array}{c}\text { Not } \\
\text { applicabl } \\
\text { e }\end{array}$ & $\begin{array}{c}40 \% \text { vs } \\
43 \%\end{array}$ \\
\hline Folfoxiri & $\begin{array}{l}\text { FOLFOXIRI } \\
\text { vs FOLFIRI }\end{array}$ & III & $\begin{array}{c}122 \text { vs } \\
122\end{array}$ & Yes & No & $\begin{array}{c}60 \% \text { vs } \\
34 \%\end{array}$ & $\begin{array}{l}22.6 \mathrm{~m} \\
\mathrm{vs} 16.7\end{array}$ & $\begin{array}{c}36 \% \text { vs } \\
12 \%\end{array}$ \\
\hline
\end{tabular}


Table 3. Characteristics and results of neoadjuvant chemotherapy trials in patients with resectable liver metastases from colorectal cancer

\begin{tabular}{|c|c|c|c|c|c|c|c|c|}
\hline $\begin{array}{l}\text { Author } \\
\text { (Year) }\end{array}$ & Therapy & Phase & $\begin{array}{l}\text { Patients } \\
\text { number }\end{array}$ & $\begin{array}{c}\text { Prospectiv } \\
\text { e }\end{array}$ & $\begin{array}{l}\text { Specially } \\
\text { designed }\end{array}$ & $\begin{array}{l}\text { OR } \\
\text { rate }\end{array}$ & $\begin{array}{c}\text { Survival } \\
\text { (\% or } \\
\text { median) }\end{array}$ & $\begin{array}{c}\% \\
\text { resectability }\end{array}$ \\
\hline $\begin{array}{c}\text { Gruenberger et } \\
\text { al (2004) }\end{array}$ & $\begin{array}{c}\text { XELOX } \\
\text { and } \\
\text { FOLFOX } \\
-4\end{array}$ & II & 50 & yes & yes & $70 \%$ & $\begin{array}{c}\text { Study } \\
\text { start: } 2003, \\
48 \% \text { alive at } \\
\text { the time of } \\
\text { publication }\end{array}$ & 100 \\
\hline $\begin{array}{c}\text { Taeib et al. } \\
(2005)\end{array}$ & $\begin{array}{c}\text { FOLFOX } \\
-7\end{array}$ & II & 22 & yes & yes & $77 \%$ & $\begin{array}{c}89 \% \text { at } 2 \\
\text { years }\end{array}$ & 91 \\
\hline $\begin{array}{c}\text { Gruenberger et } \\
\text { al (2008) }\end{array}$ & $\begin{array}{c}\text { Bevacizu } \\
\text { mab + } \\
\text { Xelox }\end{array}$ & II & $\begin{array}{c}56 \\
(19 \mathrm{pts} \\
\text { evaluabl } \\
\text { e) }\end{array}$ & yes & yes & $73 \%$ & NR & 95 \\
\hline $\begin{array}{l}\text { Nordlinger et al } \\
\text { (2008) }\end{array}$ & $\begin{array}{c}\text { FOLFOX } \\
-4\end{array}$ & III & $\begin{array}{c}182 \\
\text { (171 pts } \\
\text { evaluabl }\end{array}$ & no & yes & $43 \%$ & Not reached & 93 \\
\hline
\end{tabular}




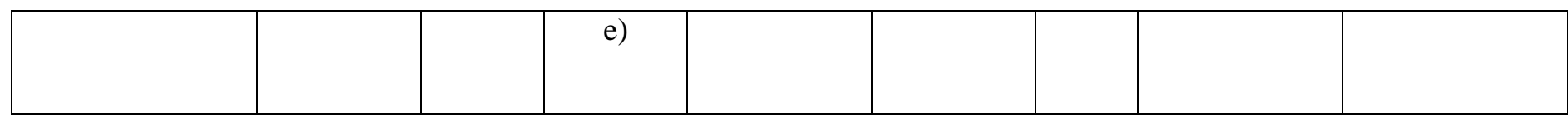

